\title{
La percepción de multitud como indicador de gestión sostenible de los cenotes de uso turístico en Yucatán, México
}

\author{
Johnathan Alexander Mondragón Mejía* \\ Universidad Nacional Autónoma de México (México) \\ Fernando Enseñat Soberanis** \\ Universidad Autónoma de Yucatán (México) \\ Rocio Blanco Gregory**** \\ Universidad de Extremadura (España)
}

\begin{abstract}
Resumen: Este artículo se centra en un estudio sobre la percepción de multitud que tiene el turista cuando visita espacios naturales de uso turístico-recreativo, como son los cenotes en la península de Yucatán, en concreto, el cenote $\mathrm{X}$ 'batún del ejido de San Antonio Mulix. La intensidad de este uso afecta al medioambiente, a la experiencia del visitante y a las comunidades locales. Estimar los límites en el número de turistas que pueden estar en un espacio natural simultáneamente demuestra ser una herramienta efectiva para una gestión sostenible. Sin embargo, la mayoría de los estudios se centran en el concepto tradicional de Capacidad de Carga Turística, priorizando los impactos al medio ambiente sobre los percibidos por el turista. Este estudio utilizó un método visual para medir la percepción de multitud de los turistas que visitan el cenote $\mathrm{X}$ 'batún y se determinaron números máximos aceptables de multitud para cada tipo de turista, (local, nacional y extranjeros) a través de curvas de normas sociales. Los resultados arrojan que los turistas locales aceptan ver 40 personas al mismo tiempo en el cenote; los nacionales 33 y los extranjeros 28 . De igual forma, se estimó la cantidad máxima que un visitante está dispuesto a pagar por diferentes niveles de multitud. El estudio discute brevemente las implicaciones de los resultados en el manejo de los cenotes.
\end{abstract}

Palabras clave: Turismo sostenible; Manejo de recursos naturales; Cenotes; Estándar de aglomeración; Normas sociales; Espacios confinados; Turistificación.

Crowding perception as an indicator of sustainable management of cenotes for tourist use in Yucatan, Mexico

Abstract: This article focuses on a study about the crowding perception the tourist has when is visiting natural areas of tourist-recreational use, such as cenotes in the Peninsula of Yucatan, specifically the cenote X'batún in the ejido of San Antonio Mulix. The intensity of this use affects the environment, the experience of the visitor and the local communities. To estimate the limits on the number of tourists that can be in a natural space simultaneously proves to be an effective tool for sustainable management. However, most of the studies focus on the traditional concept of Tourism Carrying Capacity, prioritizing the impacts to the environment on those perceived by the tourist. This study used a visual method to measure the crowding perception of the tourist that visit the cenote $\mathrm{X}$ 'batún and maximum acceptable limits for crowding were determined for different types of tourists (local, national, international) through social norms curves. Results shows that local tourists accept to see 40 people at one time at the cenote; national tourists: 33 and international tourist: 28 . The maximum amount willing to pay for different levels of crowding was also determined. The study discusses briefly management implications.

Keywords: Sustainable tourism, natural resources management, cenotes, crowding standards, social norms, confined spaces, touristification.

* Universidad Nacional Autónoma de México (México); Email: johnybc123@gmail.com

* Universidad Autónoma de Yucatán (México); E-mail: fernandoensenat@gmail.com

*** Universidad de Extremadura (España); E-mail: rblanco@unex.es 


\section{Introducción}

Se puede argumentar que el turismo, en todas sus modalidades, es una de las industrias con mayor crecimiento en el mundo actual; representa una actividad estratégica para el desarrollo económico de los países donde se realiza, de igual forma trae consigo implicaciones sociales, al incidir en el crecimiento urbano, tomando en cuenta patrones de ocupación espacial, y al influir en los procesos de conservación ambiental (Schéou, 2009; Marín y García, 2012).

En los países en vías de desarrollo, el turismo en espacios naturales es considerado como una estrategia económica que contribuye a la conservación del patrimonio natural y cultural, además de generar ingresos para las comunidades rurales (Drumm y Moore, 2002). Para el caso de la Península de Yucatán, al igual que el resto de las regiones con potencial de turismo de naturaleza en México, los pobladores rurales han subsistido con el uso de diversas actividades económicas como son: la agricultura, la ganadería, la caza, la pesca, el aprovechamiento de productos maderables y no maderables, entre otros; sin embargo, el proceso de modernización agrícola y el surgimiento de la actividad turística en la región, afectaron los precios de los productos agropecuarios y la participación de los campesinos en la economía nacional, dando pauta a la búsqueda de alternativas complementarias de ingreso (Córdoba, 1984).

En la actualidad, el turismo forma parte de las actividades que muchas comunidades rurales de la zona maya han abrazado debido a que les proporciona empleos e ingresos. Aunado al auge que ha tenido esta cultura y la promoción del simbolismo espiritual que representan los cuerpos de agua de la región (Martos, 2007), los cenotes se han vuelto parte importante de la oferta de turismo de naturaleza de la península y un foco de atención para dichas comunidades rurales que dependen de ellos, antes para realizar actividades meramente agropecuarias y ahora para un aprovechamiento turístico-recreativo. Este creciente interés está ocasionando que algunos cenotes vean un aumento exponencial en su número de visitantes con los impactos positivos y negativos que este crecimiento conlleva.

El presente trabajo propone una herramienta de planificación del turismo en cenotes turistificados a través de la estimación de la capacidad de carga perceptual que use, como indicador, el nivel de saturación de visitantes o turistas que se encuentran, al mismo tiempo, en un cenote. Y que, a su vez, sea una herramienta que ayude a los administradores de estos sitios a identificar los impactos socioeconómicos derivados de esta actividad. Hay que señalar que, aunque el concepto de la capacidad de carga ha sido relativamente poco aplicado a áreas naturales de América Latina, resulta de una gran importancia como herramienta en la gestión sostenible de los lugares turísticos, como señalan López y López (2007:27) citando a Echamendi (2001) y Vera y Baños (2004), "a pesar de las limitaciones de aplicación práctica y de su escasa aceptación, el concepto de capacidad de carga recobra un papel preponderante por el auge del paradigma de la sostenibilidad".

\section{Crowding y capacidad de carga perceptual}

El concepto de capacidad de carga no es novedoso. Sus orígenes se remontan a la teoría maltusiana que proponía en 1798 que la población crecería a un ritmo exponencial mientras que la producción de alimentos lo haría de forma aritmética generando escasez. Las primeras aplicaciones científicas de la capacidad de carga se dieron en la pesca y la ganadería en las décadas de 1920 y 1930, principalmente en el manejo de ranchos y en la vida silvestre. No fue hasta la década de 1960 que se aplicó, por vez primera, en parques naturales y espacios al aire libre, buscando estimar el uso máximo que un área natural debería tener antes de que el recurso comenzara a dañarse de manera inaceptable (Manning y Anderson, 2012).

Esta idea de "limitar" la frecuencia de visitantes bajo el argumento de daño al patrimonio genera aún mucha controversia debido a la poca evidencia científica que demuestre que, limitando el número de visitantes en un sitio, el daño disminuirá. "Establecer un punto de saturación de manera científica no es posible y, más bien, responde a una tentativa de los gestores de grandes sitios patrimoniales a usar criterios científicos improbables para legitimar sus decisiones políticas, en lugar de gestionar de otra manera los conflictos de acceso al sitio [...]. No se trata ni del patrimonio, ni del turismo, sino del ejercicio del poder. Poder para hacernos visitar un sitio patrimonial de la forma en la que ellos [los gestores] quieren que lo visitemos" (Équipe MIT, 2002:281). Así, aunque pareciera que no hay consenso sobre la importancia de calcular o no la capacidad de carga, lo cierto es que la literatura coincide en que, si bien no es un "número mágico" que solucionará los problemas de visita masiva y daño al patrimonio, sí representa una línea básica para una adecuada planificación y manejo de los espacios naturales. 
Es claro que, en sus orígenes, la capacidad de carga buscaba establecer límites en el número de visitantes y minimizar así sus impactos al medio ambiente, pero con el tiempo se volvió evidente que otros aspectos, como la experiencia del visitante, deberían también ser tomados en cuenta. En este sentido, Coccossis (2013) propone la definición de capacidad de carga del visitante como la estimación del número máximo de personas que pueden estar en un sitio sin que su presencia cause daños irreversibles en el ambiente construido y natural, y se produzca una disminución en la calidad de su experiencia.

La capacidad de carga de visitantes tiene, a su vez, tres dimensiones: la física, la perceptual y la administrativa (García Hernández, De la Calle Vaquero y Mínguez García, 2011). La capacidad de carga física se refiere al número máximo de personas que la superficie de un sitio puede recibir tomando en cuenta la superficie en metros o kilómetros cuadrados. La capacidad de carga perceptual estima el número máximo de individuos que un turista está dispuesto a ver en un área determinada antes de que su nivel de satisfacción comience a decrecer. Y, por último, la capacidad de carga administrativa se refiere al número de visitantes máximo que el personal de un sitio es capaz de manejar de acuerdo a los recursos, tanto económicos como humanos, con los que cuenta.

En esta línea y haciendo referencia al segundo concepto de capacidad de carga perceptual, autores como Roig (2003:109-110) hablan de Análisis de los Niveles de Satisfacción por parte de los usuarios presentes en espacios naturales y argumenta que "éste ha sido consignado generalmente como el principal producto resultante de una experiencia recreativa, y por tanto uno de los mayores objetivos fijados por los administradores de los recursos turísticos y recreacionales. En realidad, la satisfacción es probablemente el indicador más comúnmente usado para referirse a la calidad de la experiencia turística y recreativa. Pero la determinación de los elementos que constituyen lo que entendemos como indicador de satisfacción han sido desde siempre una tarea difícil para los investigadores sociales".

Este trabajo se centra en la capacidad de carga perceptual que, en muchas ocasiones, suele asociarse con la capacidad de carga psicosocial de los turistas o visitantes. La diferencia es que la primera está comprendida dentro de la segunda. En efecto, la capacidad de carga psicosocial es un término más amplio que considera a la capacidad de carga perceptual además de otros conceptos como el nivel de conflicto entre turistas y habitantes locales reflejado en el número máximo de turistas que un habitante local espera ver en el sitio; el nivel de conflicto por diferentes usos que se le puede dar a un mismo espacio natural (ej. ciclistas y corredores que usan un mismo sendero dentro de un Parque Nacional); y las diferentes motivaciones en función del tipo de turista (Burns, Arnberger y Von Ruschkowski, 2010).

La capacidad de carga perceptual usa como indicador el nivel de multitud o crowding para medir la aceptabilidad del turista a ver un determinado número de personas al mismo tiempo en un espacio natural. Este nivel de multitud refleja estándares o números máximos aceptables de visitantes y su variabilidad dependerá, en gran medida, de las normas personales y sociales de cada turista y de cada grupo social.

\subsection{Enfoque normativo sobre crowding}

Desarrolladas en los campos de la sociología y la psicología social, las normas han atraído considerable atención como construcción teórica y marco empírico en la investigación y la gestión de la recreación al aire libre. En particular, la teoría normativa tiene una aplicación especial para establecer estándares de multitud o saturación de visitantes en sitios recreativos.

Como se aplica en la recreación al aire libre, las normas, generalmente, se definen como estándares que los individuos y los grupos usan para evaluar el comportamiento y las condiciones sociales y ambientales. Así lo han evidenciado en sus trabajos otros autores como Donnelly, Vaske y Shelby (1992); Shelby y Vaske (1991); Vaske, Graefe, Shelby y Heberlein (1986). En esta misma línea, Manning et al. (1999) apuntan que, si los visitantes tienen normas relativas a los aspectos de las experiencias recreativas, esas normas pueden medirse y utilizarse como base para formular normas de calidad. De esta manera, la capacidad de carga perceptual se puede determinar y gestionar de manera más eficaz. Al respecto, hay que añadir el conflicto que se desprende de las normas sociales y las consecutivas sanciones sociales que pueden conllevar la no observación de dichas normas, pues las normas sociales pueden ser efectivas a nivel social y no tanto a nivel individual de las personas que visitan y hacen uso de las áreas recreativas, o, por el contrario, pueden ser más efectivas a la hora de regular el comportamiento individual y no el colectivo.

Hay que señalar que, generalmente, las normas se refieren a lo que se considera normal o aceptado dentro de un grupo social. Dichas normas representan un conjunto de reglamentos y directrices que especifican cómo se espera que las personas se comporten bajo unas condiciones particulares. 
Siguiendo a Vaske y Whittaker (2004), en psicología social, las normas se miden y se aplican fundamentalmente a través de tres paradigmas: los enfoques de normas y modelos de activación, la teoría de la acción razonada y los modelos de características estructurales. Éstos últimos se utilizan ampliamente en la formulación de normas en parques y áreas afines, y tienen como objetivo comprender las características de las normas sociales usando el Modelo de Retorno Potencial (RPM) desarrollado por Jackson en 1965. Según Jackson (1966:36), citado por Alazaizeh et al. (2015), el RPM mide la relación existente entre comportamiento y aprobación dentro de un grupo social: "representa una definición de la norma en términos de la distribución de la aprobación y la desaprobación potencial por los demás para diferentes opciones de comportamiento mostradas por los actores a lo largo de un continuo bajo condiciones especificadas, es decir, en una determinada situación definida".

Usando esta metodología, las normas personales de los turistas pueden ser utilizadas para probar la existencia de normas sociales o el grado en que las normas son compartidas entre grupos. La investigación normativa aplicada a espacios recreativos al aire libre se ha centrado, en gran medida, en el problema de la aglomeración o saturación de visitantes (Vaske y Donnelly, 1988, Shelby, Vaske y Harris, 1988). La gestión correcta de dichos grupos propone una mejora económica y social contando con el apoyo de los administradores de estos sitios.

El Modelo de Retorno Potencial, propuesto por Jackson $(1965,1966)$ (ver Fig. 1), incluye dos componentes principales: la dimensión de comportamiento (eje $\mathrm{X}$ ) que representa un número de comportamientos posibles de condiciones de un indicador en una situación particular y la dimensión de evaluación (eje Y) (por ejemplo, aceptabilidad). La curva de potencial de retorno, también denominada con frecuencia, curva de normas sociales, se representa para describir los sentimientos de los miembros del grupo sobre una dimensión específica del comportamiento en una situación concreta. Las calificaciones de actitud de los miembros individuales del grupo se promedian y sirven como base para la curva. Se pueden cuantificar varias características de la curva y, así, medir y describir diferentes atributos de las normas, tales como el intervalo de condición aceptable, la intensidad de la norma, la condición óptima o preferida, la condición mínima aceptable y la cristalización (Alazaizeh et al., 2015).

Figura 1: Curva de la norma social.

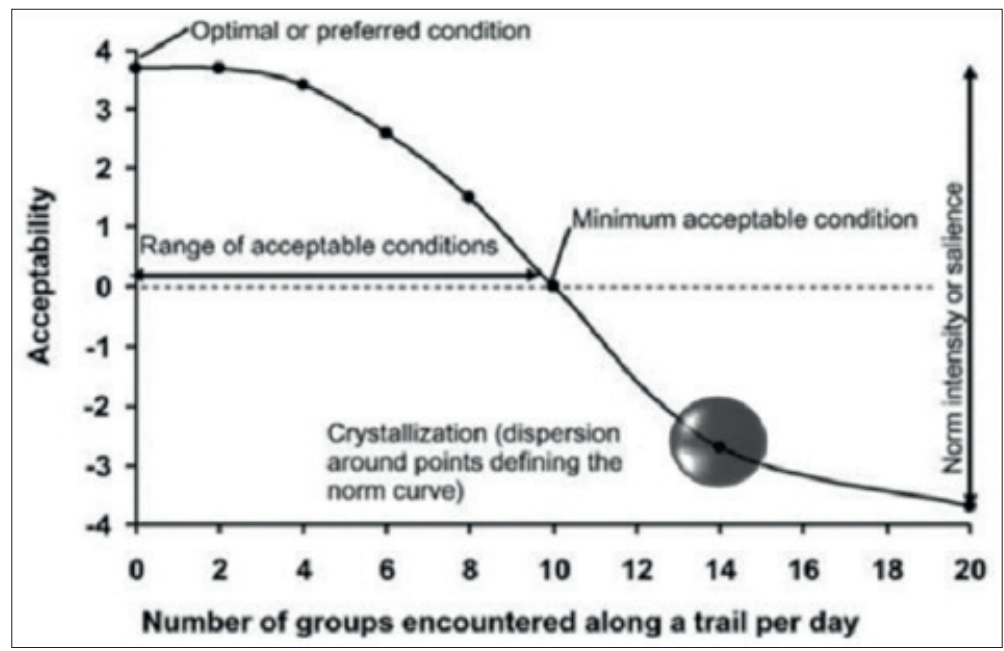

Fuente: Alazaizeh et al. (2015:3), adaptada de Manning (2007:43).

Estas normas pueden ser estudiadas usando el RPM, pidiendo a los visitantes que realicen su evaluación sobre diferentes condiciones del sitio turístico. Posteriormente, se puede graficar una curva de normas sociales con las puntuaciones de aceptabilidad media (eje X) en función del rango de condición evaluado (eje Y). La teoría normativa es, así, una garantía para desarrollar estándares y evaluar diferentes condiciones sociales, ambientales y/o de gestión en parques nacionales y áreas afines (Alazaizeh et al., 2015). 


\section{3. Área de estudio: El cenote X’batun en el Ejido San Antonio Mulix, Yucatán, México}

Los cenotes son ecosistemas característicos de la península de Yucatán, comparten rasgos únicos que permiten el desarrollo y sustento de la biodiversidad, al igual que los asentamientos humanos circundantes. El término cenote se castellanizó del vocablo maya "ts'onot" que significa "caverna con depósito de agua" (Beddows et al., 2007); Este término denota toda manifestación kárstica que alcance el nivel freático, es decir, cualquier espacio subterráneo con agua con la condición de contar con una apertura al exterior sin importar su diámetro (Gaona-Vizcayno et al., 1980).

Figura 2: Localización del Ejido San Antonio Mulix.

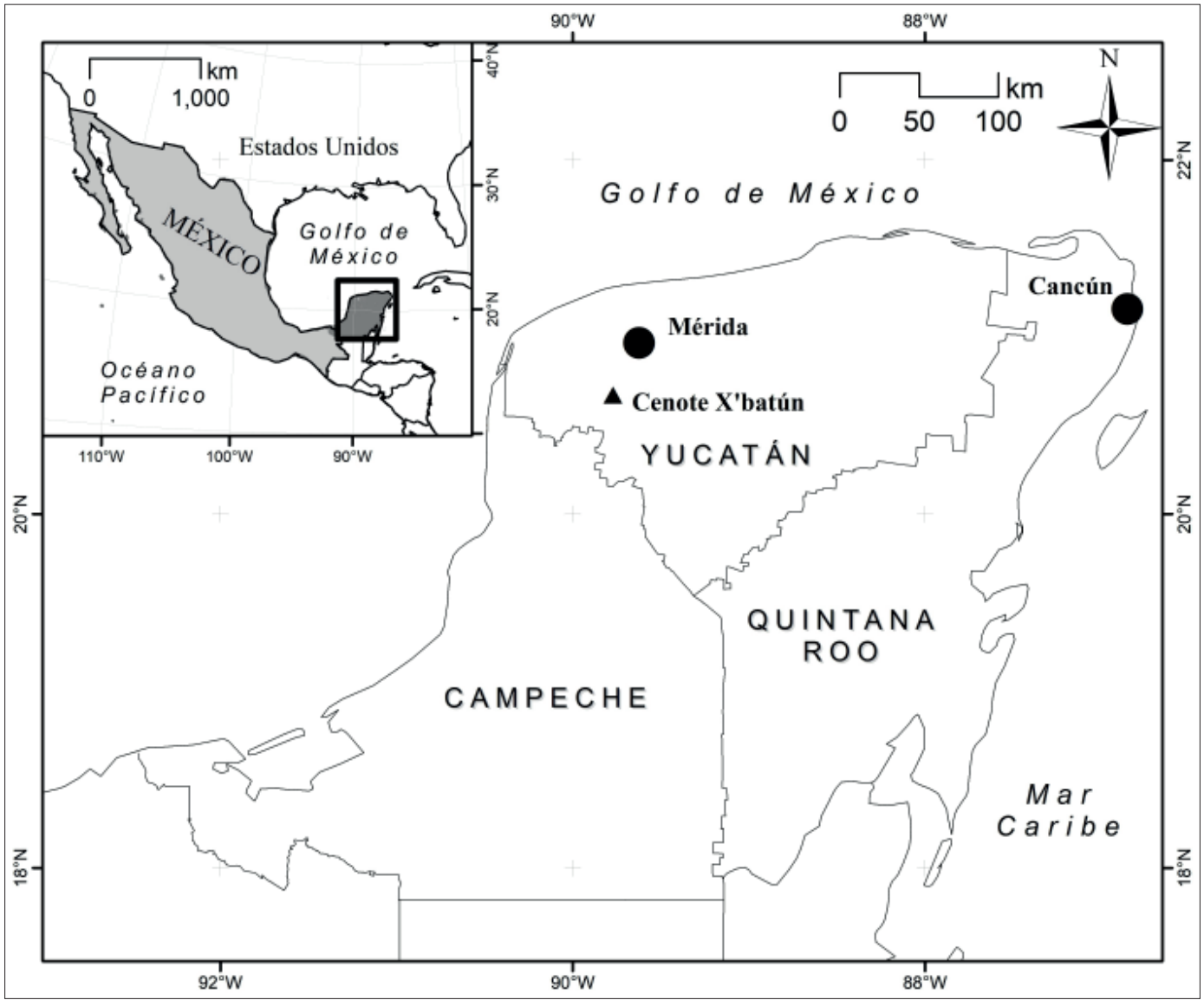

Fuente: Elaboración propia.

Estos ecosistemas poseen una gran importancia a nivel social, cultural, ecológico y económico. Históricamente, los gobernantes mayas reconocían la importancia estratégica que los cenotes representaban al permitir el acceso directo al agua subterránea, influyendo de esta manera en el desarrollo de sus asentamientos, además del significado espiritual que se les otorgaban (Martos, 2007). En términos ecológicos, los cenotes son sitios de numerosos endemismos, como la anguila ciega, Ophisternon infernale, y la dama blanca, Ogilbia pearsei, y crustáceos como Creaseria morleyi y Typhlatya campecheae (Iliffe, 1992; Reddell, 1977 y Navarro-Mendoza y Valdés-Casillas, 1990). En cuanto a la vegetación circundante, prevalece la selva mediana subperennifolia, predominante de la región de Yucatán, aunque estos ecosistemas son generalmente asociados a la presencia del álamo, Ficus cotinifolia (Reddell, 1981). 
Figura 3: Área de la superficie del espejo de agua del cenote Xbatún.

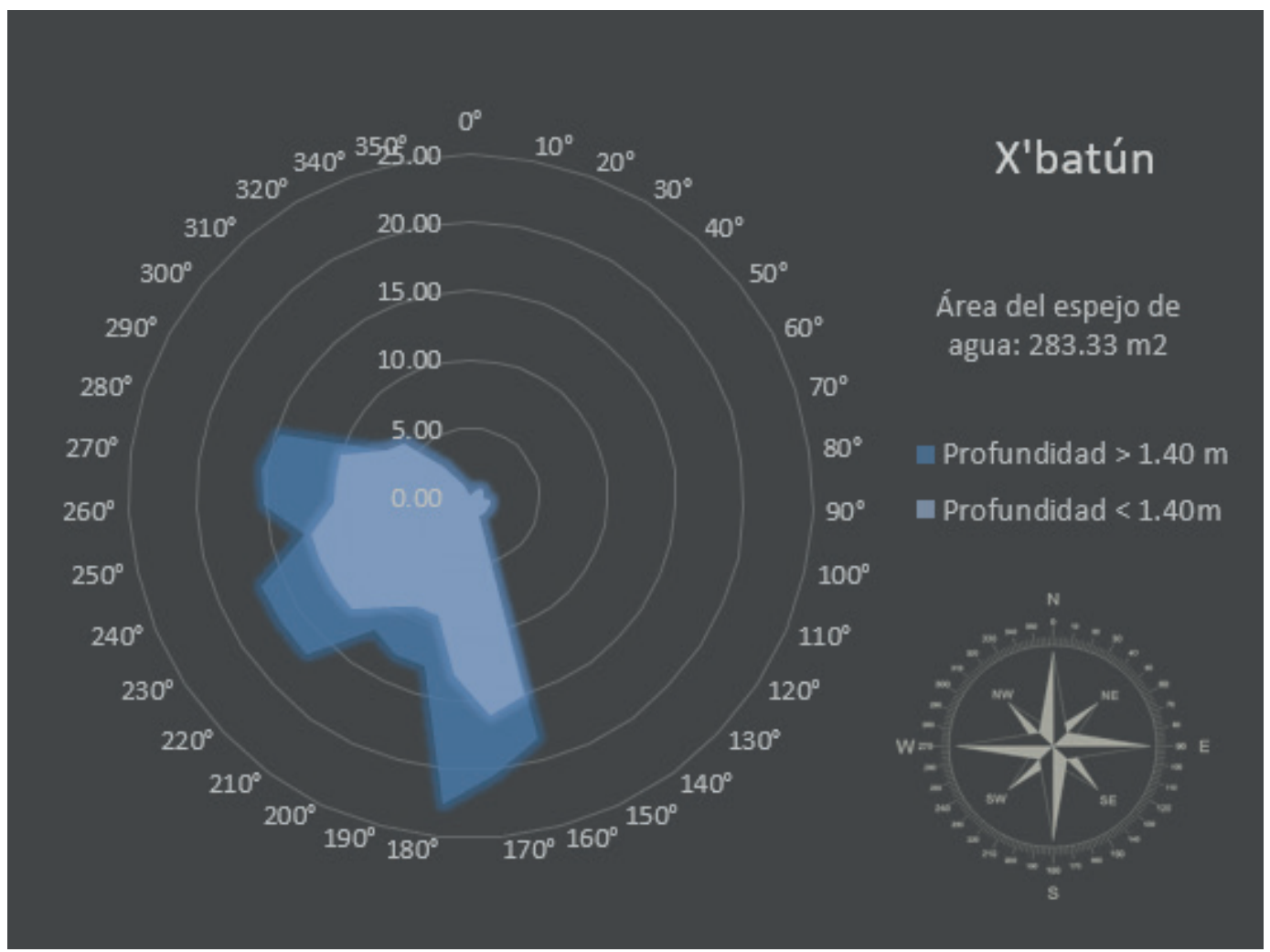

Fuente: cenoteando.org, s.f.

Para algunas comunidades de Yucatán el simbolismo espiritual que representaban estos cuerpos de agua está cambiando, se vuelve más notable el valor económico gracias al rol que juegan en el desarrollo del turismo rural (Martos, 2007). Tal es el caso de San Antonio Mulix, comisaría perteneciente al municipio de Umán en el Estado de Yucatán que, según el mapa del POETY, (Programa de Ordenamiento Ecológico del Territorio del Estado de Yucatán), se encuentra en territorio apto para realizar actividades enfocadas al turismo de bajo impacto. Se localiza a $49 \mathrm{~km}$ de Mérida (Figura 2), capital del Estado de Yucatán y cuenta con dos cenotes que se usan para fines turístico-recreativos: Dzonbacal y Xbatún. Ambos cenotes son operados por la Sociedad Cooperativa Tumben Zazil Kin Dzonot la cual es administrada por diez habitantes del ejido: 3 de ellos mujeres y 7 hombres (Herrera, C. J. C., 2013).

La ruta de más fácil acceso desde Mérida es mediante la carretera federal Muna-Uxmal. No existe transporte público hasta la entrada de los cenotes, por lo que la mayoría de los turistas llegan a bordo de autos particulares (SEDUMA, s.f.).

En términos de infraestructura, el ejido cuenta con cabañas para pasar la noche y un restaurante que ofrece comida regional elaborada por manos de sus propios habitantes. Adicionalmente, la cooperativa ofrece un servicio de alquiler de bicicletas con las cuales se puede hacer el recorrido hasta la entrada de los cenotes, equipo de snorkel para observar la fauna y flora caracteristicas de estos sitios y equipamento de campismo para pasar la noche en medio de la naturaleza. Sin embargo, los principales atractivos son, sin duda, sus cenotes Dzonbakal y X’Batún, que se localizan a un par de kilómetros de la entrada del ejido.

X'batún, se caracteriza por ser un cenote abierto de caída libre con un área de espejo de agua de $283.33 \mathrm{~m}^{2}$ (Figura 3), (cenoteando.org, s.f). Se pueden apreciar las raíces de álamo, Ficus cotinifolia, introduciendose al agua desde lo alto de la pared que se encuentra al noreste del espejo, se aprecian golondrinas, Hirundo rustica, volando en los alrededores, y nenúfares, Nymphaea ampla, en el contorno 
norte del espejo de agua. Esto sin duda influye en la decision de los turistas de visitar este sitio, sin embargo, el acontecimiento mediático que incrementó significativamente el número de visitantes en los últimos años fue la filmación de capítulos de una telenovela mexicana en sus aguas.

$\mathrm{El}$ acceso es mediante una escalera de mampostería con acabados y barandal de madera (SEDUMA, s.f.). Además, cuenta con un área de recreación de $36.6 \mathrm{~m}^{2}$, aproximadamente, que, sumado al área de espejo de agua, representa un total de $320 \mathrm{~m}^{2}$ para el uso turístico-recreativo.

X’BATÚN - Dimensiones físicas

- Área de espejo de agua: $283.33 \mathrm{~m}^{2}$

- Área de recreaci n: $36.6 \mathrm{~m}^{2}$

- Total Área para uso tur stico-recreativo: $320 \mathrm{~m}^{2}$

En los últimos años, San Antonio Mulix y sus dos cenotes, desde el punto de vista turístico, han experimentado un aumento sustancial en el número de visitantes que reciben anualmente, siendo éstos provenientes, principalmente, de la Ciudad de Mérida. En el año 2015 los cenotes recibieron 41,484 turistas, y para el año 2016 se registraron 46,767, principalmente de nacionalidad mexicana en ambos años, lo que representa un crecimiento de $12.7 \%$ en la tasa de visitantes (Figura 4).

\section{Figura 4: Visitantes mensuales en 2015 y 2016 a los cenotes del Ejido de San Antonio Mulix, Yucatán}

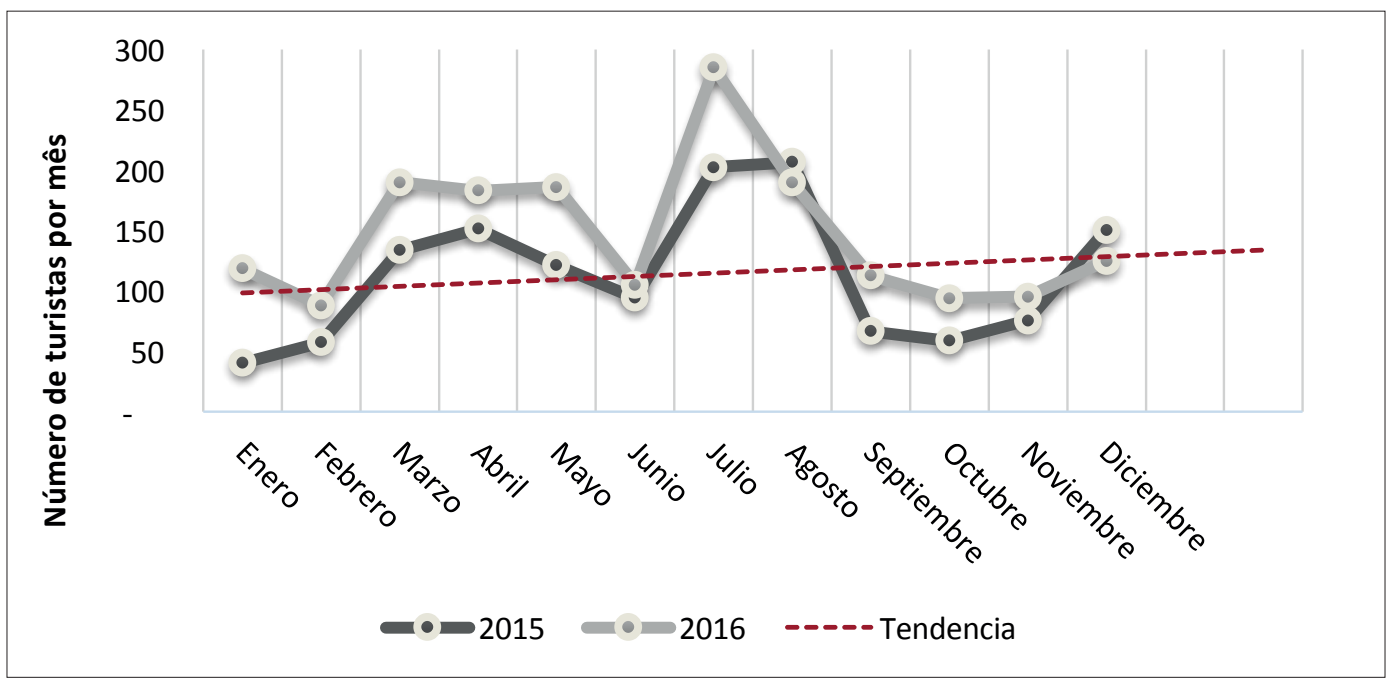

Fuente: Libro de visitas del Ejido San Antonio Mulix, Yucatán.

\section{Metodología utilizada en el estudio.}

En la literatura, generalmente, se han utilizado dos enfoques para medir la capacidad de carga perceptual en áreas naturales. De una parte, un enfoque principalmente narrativo y numérico tradicional (Shelby y Heberlein, 1986), y, de otra, una década después, un enfoque fundamentalmente de carácter visual (Manning, Lime, Freimund y Pitt, 1996). Ambos enfoques se fundamentan en solicitar a los visitantes que realicen una evaluación, basándose en sus niveles de aceptación sobre la cantidad de personas que están dispuestas a ver al mismo tiempo en un lugar determinado. Sin embargo, se ha demostrado que el enfoque visual es más adecuado para sitios con alto aforo de visitantes, ya que utiliza fotografías manipuladas por ordenador que hacen más fácil la comprensión del concepto de 
multitud (crowding), (Manning y Krymkowski, 2010; Manning, 1999). En cambio, el enfoque narrativo y numérico utiliza una descripción abstracta de las condiciones de saturación.

Así, se manipuló con Photoshop una fotografía del cenote X'batún de manera que se obtuvieran 6 láminas con diferente número de personas cada una. La primera lámina contenía cero personas y la última contenía el número máximo de personas que la densidad de uso del cenote permite. Esta densidad de uso se estimó midiendo la superficie del cenote abierta a la visita pública, es decir, el espejo de agua más toda el área de descanso localizada alrededor del cenote y donde el visitante puede estar de pie o sentarse a descansar $\left(320 \mathrm{~m}^{2}\right)$ y se dividió esta superficie entre $4 \mathrm{~m}^{2}$, que es el área vital utilizada en estudios similares (García Hernandez, 2001), dando como resultado 80 personas. Por tanto, esta cantidad (80 personas) fue la utilizada en la fotografía número 6, representando, así, el número máximo de visitantes que el cenote puede albergar a un mismo tiempo. De esta manera, la fotografía uno tenía 0 personas, la dos, 16 personas y así aumentaba en intervalos de 16 hasta la fotografía seis que contenía 80 personas. (Figura. 5).

DMU (Densidad máxima de uso) $=80$ personas

SV (Superficie Visitable) $=320 \mathrm{~m}^{2}$

AEA (Área de Espejo de Agua) $=283,33 \mathrm{~m}^{2}$

$\mathrm{AD}($ Área de Descanso $)=36,66 \mathrm{~m}^{2}$

$\mathrm{AV}($ Área Vital $)=4 \mathrm{~m}^{2}$

Las fotografías, junto con un cuestionario, fueron mostradas a 196 visitantes, de los cuales 100 fueron mujeres y 96 hombres, el $72 \%$ de los encuestados tenían entre 18 y 44 años de edad y el $43 \%$ de los encuestados contaban con una licenciatura terminada. Se obtuvo una tasa de respuesta del 51\% (196), de los cuales el 55.1\% fueron residentes locales, es decir, del estado de Yucatán, principalmente de Mérida y los municipios localizados alrededor de San Antonio Mulix. El 35.7\% fueron visitantes nacionales, considerados como todos los residentes de otros estados de México diferentes a Yucatán; y el 9.2\% correspondió a visitantes extranjeros. Se usó un muestreo no probabilístico por conveniencia y se determinó el tamaño de la muestra utilizando la calculadora estadística disponible en línea www. netquest.com. Para el tamaño del universo se consideró el número total de visitantes del $2016(46,767)$, un margen de error del 5\% y un nivel de confianza del 95\%. La muestra obtenida es representativa de la población universo.

A cada visitante se le mostraron las 6 fotografías, una por una, y se le pidió que las evaluara en un escala de 9 puntos, desarrollada por Heberlein y Vaske (1977) que va de 1= nada congestionado a $9=$ extremadamente congestionado. Esta escala de 9 puntos permite generar la curva de norma social teniendo un punto medio igual a cero y 4 niveles positivos arriba y 4 negativos por debajo del cero (Figura 1). Esta escala de 9 puntos ha demostrado ser la más efectiva para medir la percepción de multitud como se demuestra en los más de 181 diferentes estudios en los que se ha aplicado (Vaske y Shelby, 2008). Asimismo, se les pidió expresar la cantidad más alta dispuesta a pagar por entrar al cenote con el número de personas fijada en cada fotografía. La intención de esta pregunta era medir la disposición de los visitantes a pagar más por sitios menos saturados. Esta distinción entre visitantes locales, nacionales y extranjeros se hizo para poder identificar si existen diferencias en el nivel de aceptación en función del lugar de residencia del visitante o turista. 
Figura 5: Las seis láminas manipuladas con Photoshop y utilizadas en el estudio.

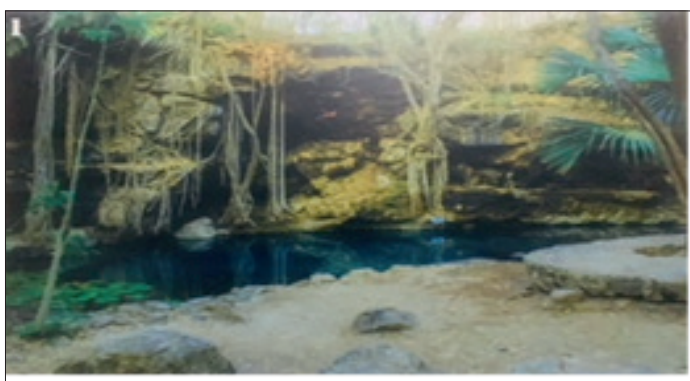

Foto l: D personas

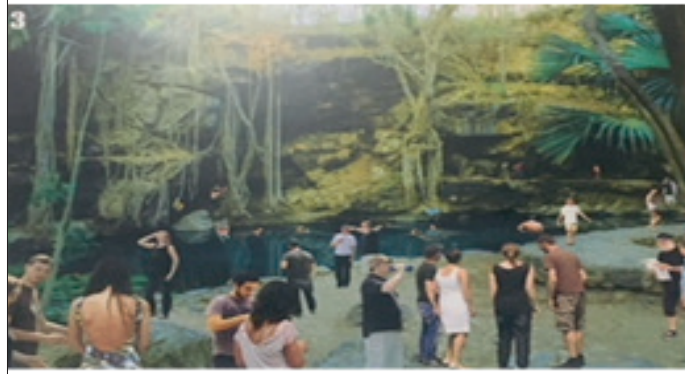

Foto 3: 32 personas

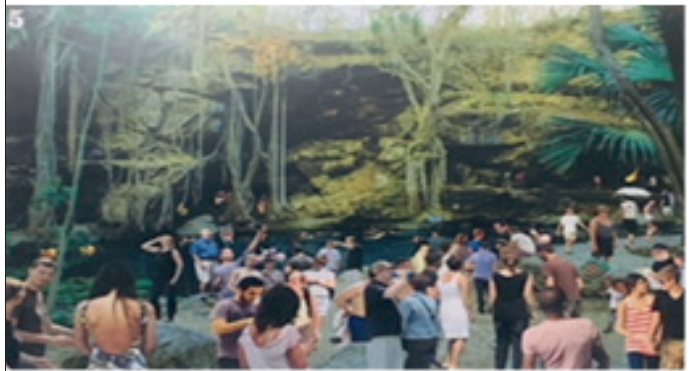

Foto 5 : 64 personas

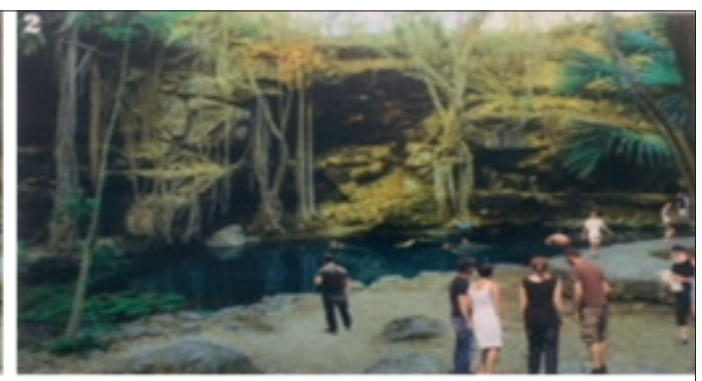

Foto 2: I6 personas

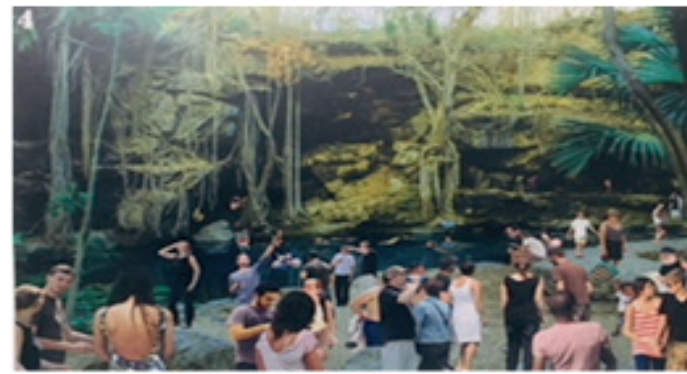

Foto 4: 48 personas

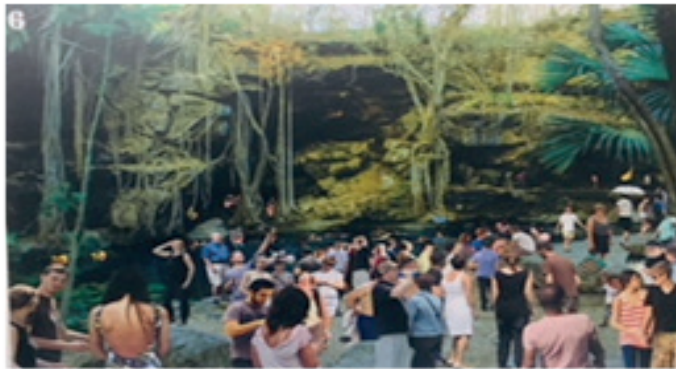

Foto 6: 80 personas

Fuente: Elaboración propia.

\subsection{Cristalización de la norma.}

El grado de consenso entre la muestra se indica por la dispersión o la varianza de las respuestas individuales alrededor de los promedios de aceptación que definen la curva de normalidad se le define como cristalización de la norma (Manning et al., 1999) y se entiende como la anuencia de los visitantes con respecto a la evaluación de una misma situación presentada, en este caso, de la evaluación que tienen todos los informantes sobre la misma fotografía. Para estimar la cristalización de norma se usó el Índice de Conflicto Potencial ( $\mathrm{PCI}_{2}$, por sus siglas en inglés), como medida de dispersión de los datos, el cual puede tomar valores dentro del rango de 0 a 1, donde el 0 representa una situación con el nivel de conflicto potencial más bajo y el más alto nivel de consenso. Y, por el contrario, el 1 representa la situación con mayor potencial de conflicto y el mínimo nivel de consenso por parte de los encuestados. Los valores de $\mathrm{PCI}_{2}$ se calcularon utilizando una hoja de cálculo de Excel programada para realizar dicha prueba estadística, la cual se encuentra en http://warnercnr.colostate.edu/jerryv/ calculating-pci2-excel/ . 


\section{Resultados obtenidos}

El rango del número de turistas que aparece en las fotografías varía de 0 a 80 individuos y la escala de aceptación es de +4 a -4 (Figura 6).

Figura 6: Curvas de norma social de aceptación al número de visitantes simultáneamente en el cenote Xbatún.

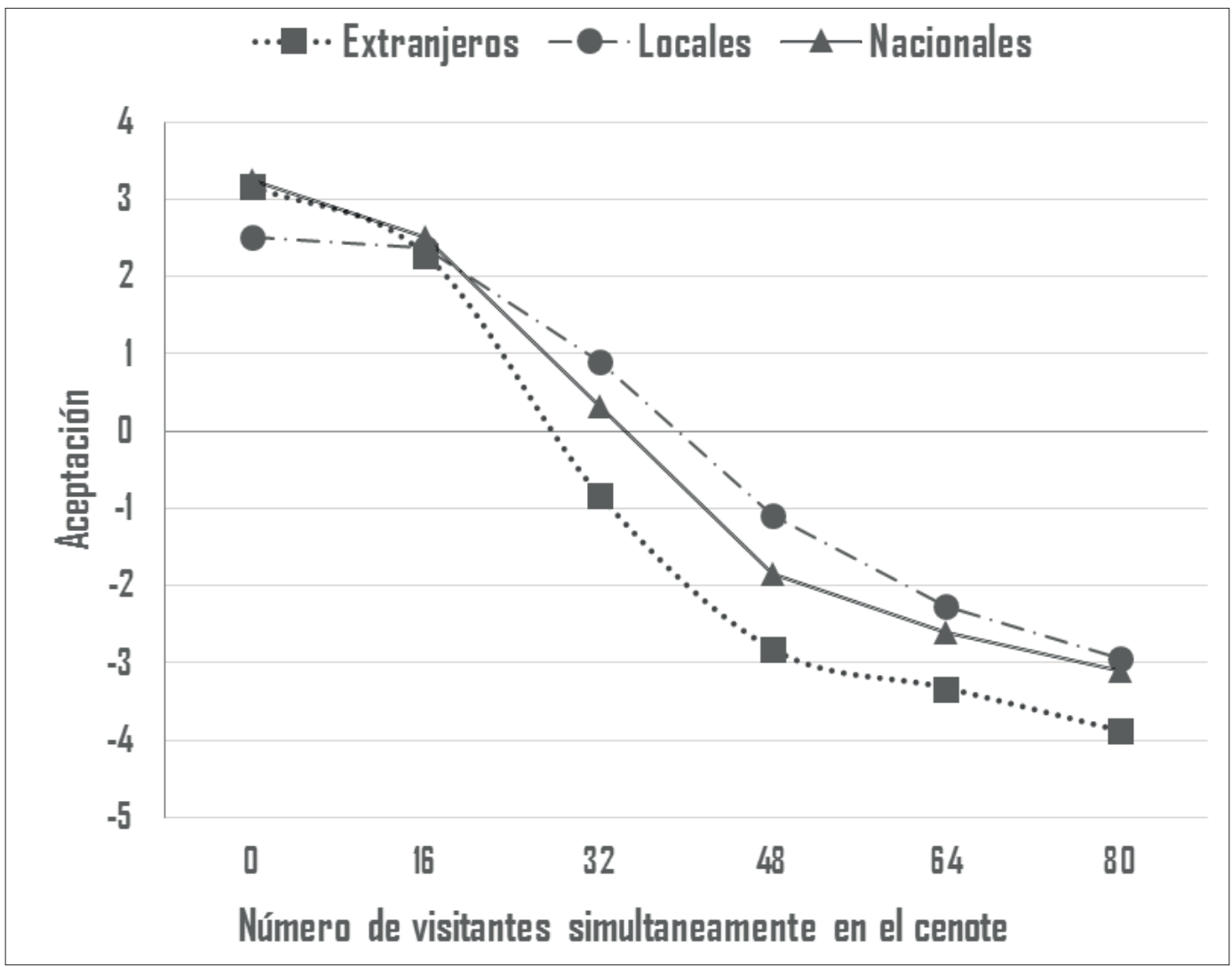

Fuente: Elaboración propia.

Como se puede observar en la figura 6, los resultados demuestran que para los tres grupos de visitantes el nivel de aceptación decrece a medida que el número de visitantes simultáneamente aumenta. En el caso de los locales, el promedio de aceptación pasa de +2.5 para la fotografía con 0 personas a -3 para la fotografía con 80 personas. Para los visitantes nacionales, este nivel va de +3.2 a -3.1 y para los extranjeros, el rango varía de +3.2 a -3.9. Un cenote sin personas genera el nivel de aceptación óptimo en los tres tipos de visitantes. El rango de aceptación para los visitantes locales es de 0 a 40 personas al mismo tiempo en el cenote. Para los nacionales es de 0 a 33 personas y para los extranjeros es de 0 a 28 personas. Es decir, los rangos de aceptación varían de 28 a 40 personas al mismo tiempo en el cenote, siendo los visitantes extranjeros, los que registran niveles de aceptación más bajos y los visitantes locales, los más altos.

Cristalización de la norma: $\mathrm{PCI}_{2}$

Los valores del Índice Potencial de conflicto $\left(\mathrm{PCI}_{2}\right)$ fueron utilizados para estimar la cristalización de la norma (Vaske y Whittaker, 2004). El rango de los valores de $\mathrm{PCI}_{2}$ varía de 0 a 1, donde el 0 
indica el más bajo nivel de conflicto y el 1 indica el nivel más alto de conflicto. Es decir, mientras más grande es el círculo, mayor es el nivel de conflicto y más bajo el nivel de consenso. Los círculos pequeños indican alto consenso y bajo conflicto, esto se puede observar en las figuras 7,8 y 9 , donde se muestran las curvas de normas sociales de cada uno de los diferentes tipos de turistas: locales, nacionales y extranjeros y la cristalización de cada norma expresada por el Índice Potencial de Conflicto $\left(\mathrm{PCI}_{2}\right)$.

La figura 7 representa el nivel de consenso existente entre los visitantes locales con respecto al nivel de aceptación de un cenote en el gradiente de multitud presentado en cada una de las láminas mostradas. La figura 8 representa a los visitantes nacionales mientras que la figura 9 representa a los visitantes extranjeros. En las tres figuras se expresa el nivel de consenso para cada una de las láminas presentadas mediante burbujas.

En general, para los tres tipos de visitantes, las fotografías de los extremos, con 0, 16 y 80 personas respectivamente, son las que presentan niveles de conflicto más bajos. Es decir, hay un alto nivel de consenso o acuerdo de los visitantes locales, nacionales y extranjeros respecto al nivel de aceptación de un cenote vacío y semi-vacío y de un cenote excesivamente lleno. Los niveles de desacuerdo o conflicto más altos se observan en las fotografías 3,4 y 5 con 32, 48 y 64 personas simultáneamente en el cenote. Es decir, hay mayor dificultad para ponerse de acuerdo en el nivel de aceptación de un cenote con niveles medios de aglomeración que en el caso de cenotes vacíos o muy llenos. Para los visitantes locales, el rango de valores del $\mathrm{PCI}_{2}$ va de 0.13 a 0.4 (Figura 7). Para los visitantes nacionales de 0.15 a 0.37 (Figura 8) y para los extranjeros de 0.01 a 0.19 (Figura 9). Los visitantes extranjeros tienen mayor consenso en todas las situaciones presentadas en las láminas en contraste con el resto de los visitantes encuestados.

Figura 7: Curva de norma social correspondiente a los visitantes locales.

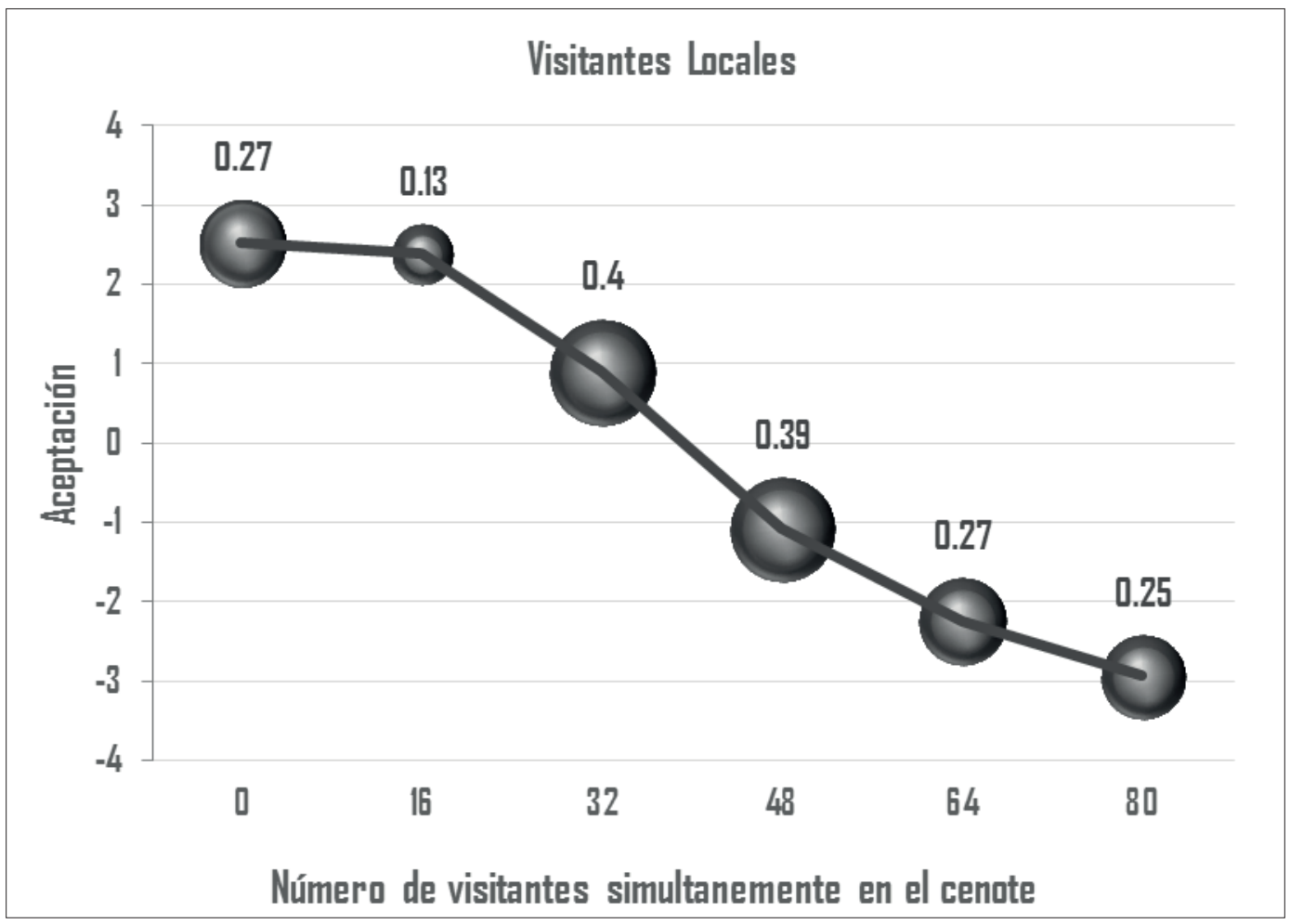

Fuente: Elaboración propia. 
Figura 8: Curva de norma social correspondiente a los visitantes nacionales.

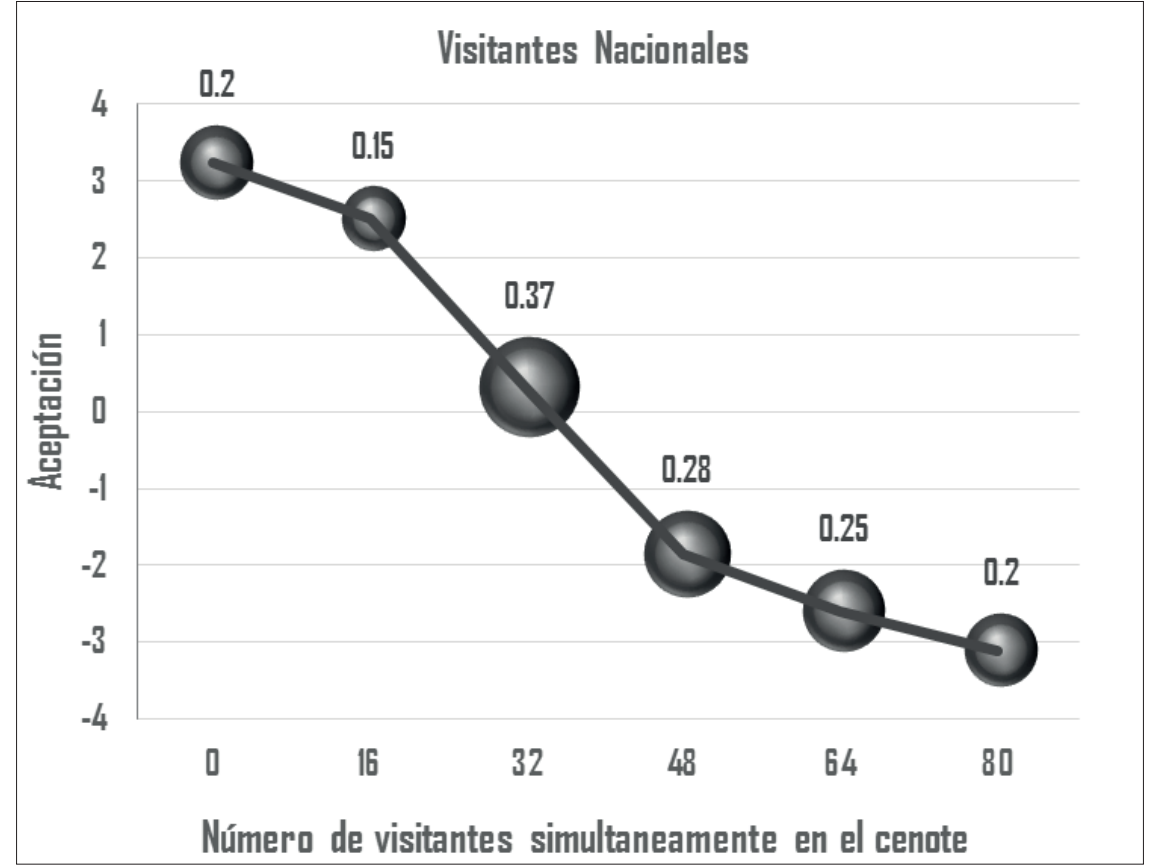

Fuente: Elaboración propia.

Figura 9: Curva de norma social correspondiente a los visitantes extranjeros.

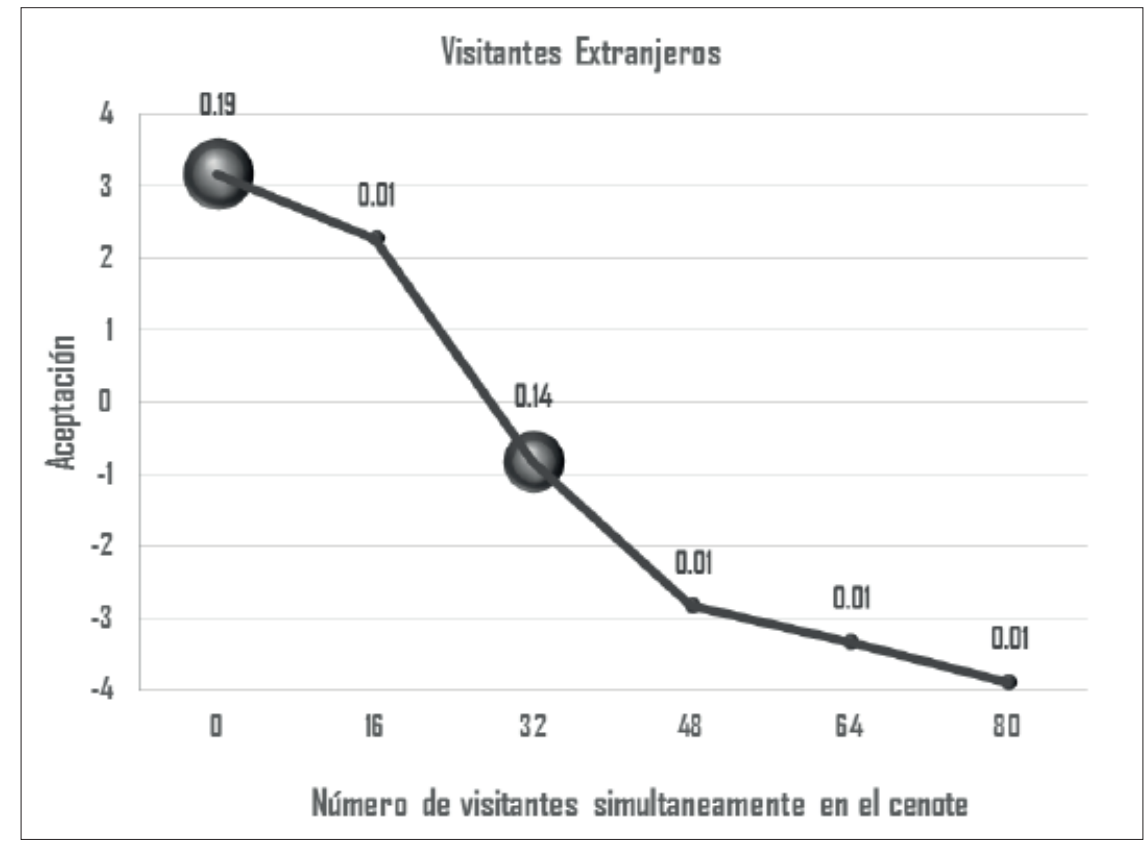

Fuente: Elaboración propia. 
Disposición máxima a pagar por entrar a un cenote.

Por otro lado, la disposición a pagar por entrar a un cenote, varía en función del número de personas al mismo tiempo que en él se encuentren. Se observa una tendencia general a querer pagar más por un cenote vacío o con pocas personas y a pagar menos por un cenote saturado (Figura 10).

Sin embargo, existen diferencias entre visitantes locales, nacionales y extranjeros. Los locales tienen menos disposición a pagar tarifas altas por hacer uso de un cenote vacío o con pocas personas en comparación con los nacionales y extranjeros (\$68.29 pesos de un local en comparación con $\$ 139.54$ pesos de un nacional y $\$ 111.69$ pesos de un extranjero). Las diferencias entre las cantidades máximas y mínimas a pagar por cada tipo de visitante son: para locales, $\$ 61.94$ pesos; para nacionales, $\$ 104.64$ y para extranjeros, $\$ 106.97$ pesos.

Figura 10: Cantidades dispuestas a pagar por número de visitantes simultáneamente en el cenote Xbatún.

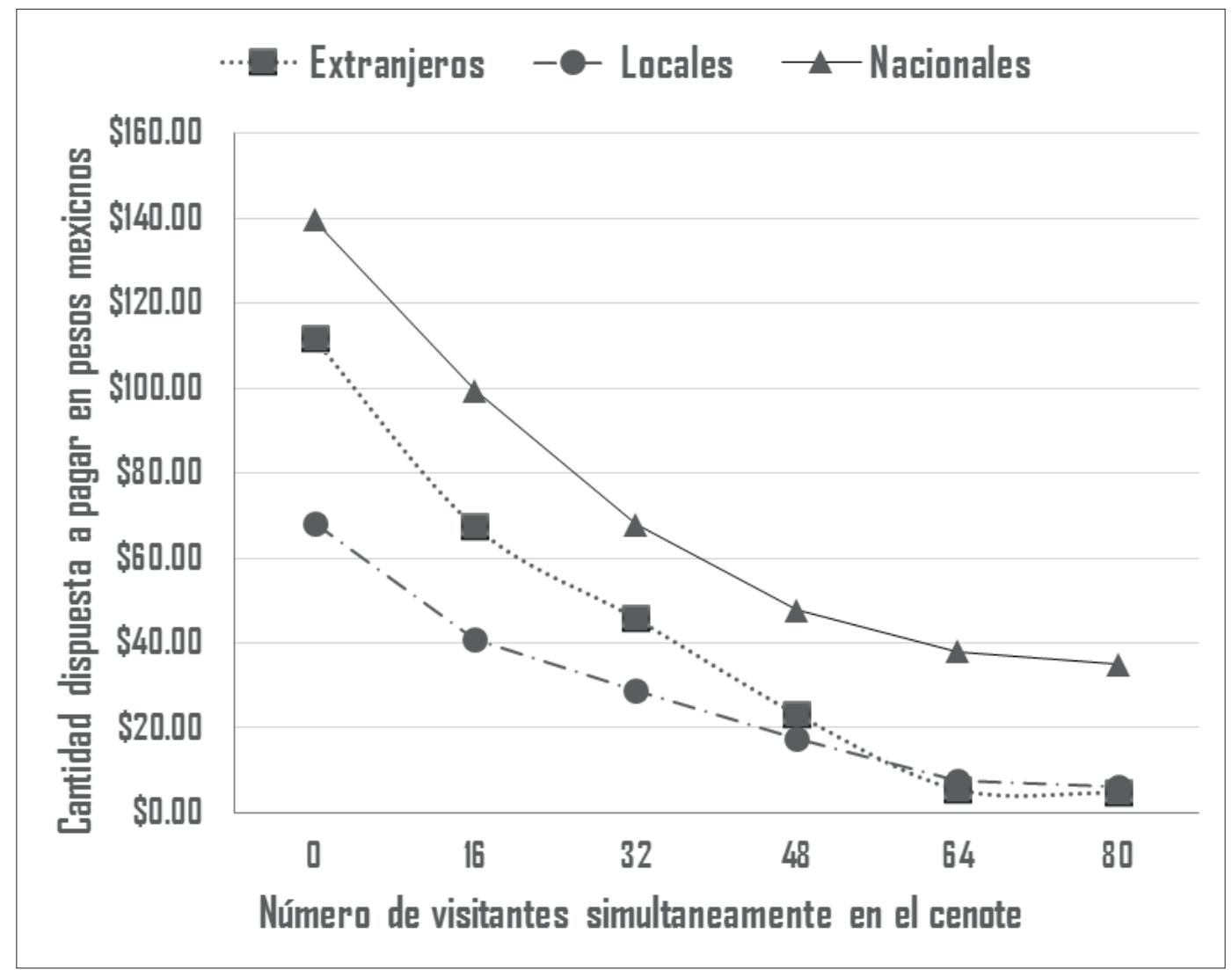

Fuente: Elaboración propia.

\section{Discusión y Conclusión}

El turismo en México duplicó el crecimiento del turismo mundial con una tasa del 9,5 \% en 2015 en relación con el año anterior (SECTUR, 2016). Se trata de la industria que ha sufrido el crecimiento más rápido en el siglo XX. Evidentemente, esta situación conlleva a fuertes inyecciones de dinero para los destinos y aumenta, en muchas ocasiones, el riesgo de una masificación de los sitios, lo cual podría 
tener implicaciones negativas en la conservación del patrimonio natural y cultural de las comunidades y en la calidad de la experiencia de los visitantes.

Los resultados de este estudio tienen implicaciones sobre la gestión de los cenotes ya que pueden ser utilizados como una herramienta para mejorar su uso turístico e influir positivamente en la sostenibilidad del lugar. Wagar (1964) señala que mientras más turistas reciba un sitio, no solo los recursos naturales se verán afectados, sino que también tendrá un impacto en la calidad de la experiencia del visitante. En el caso del cenote X'batún, estos impactos repercuten en última instancia en el ámbito económico de la cooperativa. Si el visitante no tolera el alto número de personas que hay en el momento de su ingreso al cenote, existen altas probabilidades de que no vuelva o manifieste su experiencia negativa a familiares y amigos.

Shelby et al. (1989) mencionan que el nivel de aceptación de un turista es inversamente proporcional a la cantidad de turistas que permanecen en el sitio, es decir, a mayor multitud menor será la aceptación del visitante. Manning et.al (1996) resaltan la existencia de un número considerable de literatura que evidencia que las características de los visitantes pueden influir en la evaluación de la percepción de la multitud. En el caso de X’batún se clasificaron los turistas en locales, nacionales y extranjeros.

Shelby et al. (1989) concuerdan con que la percepción de multitud de un turista varía en función a su nacionalidad e incluso dependiendo de la región del país de procedencia. De estos tres tipos de turistas, los locales mostraron mayor tolerancia a situaciones de aglomeración con no más de 40 personas simultáneamente como aceptable antes de que su experiencia de visita se torne insatisfactoria. Los turistas nacionales consideran no más de 33 personas como aceptable, mientras que los extranjeros calificaron su experiencia como satisfactoria al no exceder de 28 personas simultáneamente en el cenote. Los locales aceptan ver un número más alto de personas al mismo tiempo en el cenote y son ellos quienes otorgaron la menor calificación a un cenote vacío y la mayor a un cenote saturado.

Manning et al. (1996) señalan que el método visual es más efectivo que el método tradicional numérico y narrativo, utilizado por autores como Vaske, Shelby \& Heberlin (1986), para la medición de la percepción de la multitud. Así mismo, diversos autores (Manning, Line, Freimund \& Pitt, 1996; Manning \& Anderson, 2012; Alazaizeh, 2015) concuerdan en que la cristalización de la norma es mayor utilizando el método visual, es decir, hay mayor consenso por parte de los turistas al calificar situaciones visuales en contraste con narrativas-descriptivas, sobre todo en sitios con alto aforo. Se puede afirmar que los tres tipos de visitantes manifiestan dificultades al coincidir en la evaluación de situaciones intermedias, es decir, hay menos consenso en estas situaciones. Al contrario, los valores de PCI en las situaciones de un cenote vacío y un cenote saturado fueron los más bajos otorgadas por los turistas dentro del rango de 0.01 a 0.2 , es decir, existe mayor consenso.

Tomando en cuenta el aspecto económico con respecto a la cantidad monetaria que el turista estaría dispuesto a pagar como precio de entrada al lugar, hay que señalar que en los tres tipos de turistas (locales, nacionales y extranjeros), se observa una relación inversamente proporcional entre la cantidad dispuesta a pagar y el número de visitantes que se le muestran en las fotografías, siendo los turistas nacionales los que están dispuestos a pagar más por un cenote con menos personas (\$139.54 pesos); seguido de los extranjeros (\$111.69 pesos) y, por último, los locales ( $\$ 68.29$ pesos). El reto de los administradores del cenote reside en fijar cuotas de entrada diferenciadas por la procedencia del visitante que no rebasen el máximo dispuesto a pagar, asegurando una experiencia de visita satisfactoria.

Estos hallazgos podrían ser de utilidad para advertir a los administradores de recursos naturales sobre los problemas potenciales que conlleva la aglomeración.

Si bien, este estudio provee datos útiles que permiten a los administradores de X'batún entender mejor los desafíos de multitud a los que se enfrentan, aún son necesarias futuras investigaciones que fortalezcan las generalizaciones de estos descubrimientos. Los resultados encontrados son útiles para el establecimiento de límites de multitud, así mismo, podrían ser la base para la creación de planes de gestión por parte de los administradores del sitio que contribuyan al buen funcionamiento y manejo sostenible del cenote X'batún, considerando el tipo de turista, la experiencia de visita y la cantidad máxima dispuesta a pagar, tratando siempre de evitar la masificación del sitio. Se trata de encontrar un punto medio entre una elitización del sitio que lo reserve a ciertos tipos de turistas que pueden pagar una tarifa alta por estar en un lugar exclusivo y sin gente; y la masificación que hace accesible el cenote, con tarifas bajas, al gran público. 


\section{Agradecimientos}

Al Consejo Nacional de Ciencia y Tecnología (CONACyT) por la asignación de una Beca-Mixta que contribuyó a la realización de esta investigación.

Al Proyecto Europeo IRSES-GA-2013-612686 - EcoDry "Sharing Best Agroecological Practice for Resilient Production Systems in Dryland and Drought Conditions" por la financiación de una estancia de investigación en la Universidad Autónoma de Yucatán (UADY), Mérida (Yuc.), México, durante los meses de marzo y abril de 2017.

A la investigadora Dra. Maite Mascaró Miquelajauregui de la Universidad Nacional Autónoma de México, por su asesoramiento en ciertos aspectos del estudio empírico.

\section{Bibliografía}

Alazaizeh, Mohammad M., Hallo, Jeffrey C., Backman, Sheila J., Norman, William C. \& Vogel, Melissa A. 2015. Crowding standards at Petra Archaeological Park: a comparative study of McKercher's five types of heritage tourists. Journal of Heritage Tourism, 11 (4), 364-381.

Beddows, Patricia, Blanchon, Paul, Escobar, Elva y Torres-Talamante, Olmo 2007. Los cenotes de la península de Yucatán. Arqueología mexicana, 83, 32-35.

Burns, Robert C., Arnberger, Arne, \& Von Ruschkowski, Erick 2010. Social Carrying Capacity Challenges in Parks, Forests, and Protected Areas: An Examination of Transatlantic Methodologies and Practices. International Journal of Sociology, 40 (3), 30-50

Cenoteando.org . S.F. Página web en desarrollo creada por estudiantes de la Licenciatura en Manejo Sustentable de Zonas Costeras de la UNAM, Sisal. Recuperado de www.cenoteando.org

Coccossis, Harry 2013. Carrying Capacity as a tool for the Management of Tourism Pressures on Heritage Sites. In N. Agnew \& M. Demas (Eds.), Visitor Management and Carrying Capacity at World Heritage Sites in China (pp. 35-38). Mogao Grottoes, China: The Getty Conservation Institute.

Córdoba, Juan 1984. Descentralización, territorio y ambiente en la Península de Yucatán: una mirada geográfica desde el enfoque de centralidad. Mérida, México: CINVESTAV.

Donnelly, Maureen P., Vaske, Jerry J. \& Shelby, Bo 1992. Establishing management standards: Selected examples of the normative approach. In B. Shelby, G. Stankey, \& B. Shindler (Eds.), Defining wilderness quality: The role of standards in wilderness management. A workshop proceedings (USDA Forest Service General Technical Report PNW-305).

Drumm, Andy \& Moore, Alan 2002. Desarrollo del ecoturismo: Un manual para los profesionales de la conservación, The Nature Conservancy, Arlington, Virginia (USA)

Echamendi Lorente, Pablo 2001. La capacidad de carga turística. Aspectos conceptuales y normas de aplicación. Anales de Geografía de la Universidad Complutense, 21, 11-30.

Équipe MIT. 2002. Tourism 1. Lieux communs. Paris: Éditions Belin.

Gaona-Vizcayno, Salvador, Gordillo de Anda, Tuchée y Villasuso-Pino, Miguel 1980. Cenotes, karst característico: mecanismos de formación. Rev. Univ. Nac. Autón. México, 4(1), 32-36.

Gaona-Vizcayno, Salvador, Gordillo de Anda, Tuchée y Villasuso-Pino, Miguel 1980. Cenotes, karst característico: mecanismos de formación. Rev. Univ. Nac. Autón. México, 4(1), 32-36.

García Hernández, María, De la Calle Vaquero, Manuel y Mínguez García, Ma del Carmen 2011. Capacidad de carga turística y espacios patrimoniales. Aproximación a la estimación de la capacidad de carga del conjunto arqueológico de Carmona (Sevilla, España). Boletín de La Asociación de Geógrafos Españoles, 57, 439-441.

Herrera, Carolina Judith C. 2013. Explaining autonomy in community-based ecotourism: A comparative study of two proyects un Yucatan, Mexico. Tesis de grado no publicada del Departamento de Geografía, Universidad de Londres. King's College London. MA degree in Tourism, Environment and Development. Londres, Inglaterra.

Iliffe, Thomas M. 1992. An annotated list of the troglobitic anchialine and freshwater fauna of Quintana Roo. En D. Navarro y E. Suárez-Morales (Eds.): Diversidad Biológica en la Reserva de la Biosfera de Sian Ka’an, Quintana Roo, México, 2: 197-217. México: Secretaría de Desarrollo Social (SEDESOL).

Jackson, Jay 1965. Structural characteristics of norms. In I. D. Steiner \& M. Fishbein (Eds.), Current studies in social psychology (pp. 301-309). New York, NY: Holy, Rinehart and Winston.

Jackson, Jay 1966. A conceptual and measurement model for norms and roles. The Pacific Sociological Review, 9(1), 35-47. 
López Bonilla, Jesús Manuel y López Bonilla, Luis Miguel 2007. La capacidad de carga psicológica del turista como indicador del turismo sostenible. Boletín ICE económico, (2911), 25-35.

Manning, Robert E. 1999. Crowding and carrying capacity in outdoor recreation from normative standards to standards of quality. In E. L. Jackson \& T. L. Burton (Eds.): Leisure studies: Prospects for the twenty-first century (pp. 323-334). State College, PA: Venture Publishing.

Manning, Robert E. \& Anderson, Laura E. 2012. Managing outdoors recreation: Case Studies in the National Parks. Wallingford, UK: CABI Publishing.

Manning, Robert E. \& Krymkowski, Daniel H. 2010. Standards of quality for parks and protected areas. International Journal of Sociology, 40(3), 11-29.

Manning, Robert E., Lime, David W., Freimund, Wayne A. \& Pitt, David G. 1996. Crowding norms at frontcountry sites: A visual approach to setting standards of quality. Journal of Leisure Sciences, 18, 39-59.

Manning, Robert E., Valliere, William A. \& Wang, Benjamin 1999. Crowding Norms: Alternative Measurement Approaches. Journal of Leisure Sciencies, 21(2), 97-115.

Martos, Luis Alberto 2007. Los cenotes en la actualidad, entre la veneración y la explotación. Arqueología Mexicana 83, 32-35.

Navarro-Mendoza, Mario y Valdés-Casillas, Carlos 1990. Peces cavernícolas de la Peninsula de Yucatan en peligro de extinción, con nuevos registros para Quintana Roo. En: J.L. Camarillo y F. Rivera A. (Eds.): Áreas Naturales Protegidas en México y Especies en Extinción. (pp. 218-241). Universidad Nacional Autónoma de México, Ciudad de México.

Reddell, James R. 1977. A preliminary survey of the caves of the Yucatan Peninsula. Assoc. Mex. Cave. Stud. Bull., 6, 215-296.

Reddell, James R. 1981. A review of the cavernicole fauna of Mexico, Guatemala, and Belize. Texas Mem. Mus. Bull, 27, 1-327.

Roig i Munar, Francesc Xavier 2003. Análisis de la relación entre capacidad de carga física y capacidad de carga perceptual en playas naturales de la isla de Menorca. Investigaciones Geográficas, 31, 107-118.

SECTUR 2016, 17 marzo. El Turismo en México aumentó más del doble del crecimiento mundial en 2015. Secretaría de Turismo Prensa. Recuperado de www.gob.mx/sectur/prensa/el-turismo-en-mexico-aumento-mas-del-doble-del-crecimiento-mundial-en-2015

SEDUMA S.F. CENOTES: Ficha Técnica. Recuperado el 5 de agosto de 2017, de http://www.seduma. yucatan.gob.mx/cenotes-grutas/fichastecnicas/Yucatan_Uman_cenote_Dzonbacal.pdf

Shelby, Bo \& Heberlein, Thomas A. 1986. Carrying capacity in recreation settings. Corvallis, Oregon State: University Press.

Shelby, Bo \& Vaske, Jerry J. 1991. Using normative data to develop evaluative standards for resource management: A comment on three recent papers. Journal of Leisure Research, 23, 173-187.

Shelby, Bo, Vaske, Jerry J. \& Harris, Rick 1988. User standards for ecological impacts at wilderness campsites. Journal of Leisure Research, 20, 245-256.

Schéou, Bernard 2009. Du tourisme durable au tourisme équitable: Quelle éthique pour le tourisme de demain?. Paris: De Boeck Supérieur.

Vaske, Jerry J. \& Whittaker, Doug 2004. Normative approaches to natural resources. In M. J. Manfredo, J. J. Vaske, B. L. Bruyere \& D. R. Field (Eds.): Society and natural resources: A summary of knowledge (pp. 283-294). Jefferson, MO: Modern Litho.

Vaske, Jerry J. \& Donnelly, Maureen P. 1988. Normative evaluations of wildlife management. Paper presented at the Annual Congress of the National Recreation and Park Association, Indianapolis, Indiana.

Vaske, Jerry J., Graefe, Alan R., Shelby, Bo \& Heberlein, Thomas A. 1986. Backcountry encounter norms: Theory, method, and empirical evidence. Journal of Leisure Research, 18, 137-153.

Vera Rebollo, José Fernando. y Baños Castiñeira, Carlos Javier 2004. Turismo, territorio y medio ambiente. Papeles de Economía Española, 102, 271-286.

Wagar, J. A. 1964. The carrying capacity of wild lands for recreation. Forest Science, Monograph 7, Society of American Foresters, Washington DC.

Recibido: 